\title{
Mini-chromosomes in Fusarium sporotrichioides are mosaics of dispersed repeats and unique sequences
}

\author{
Richárd Nagy, ${ }^{1}$ Éva Táborhegyi, ${ }^{1}$ Anita Wittner ${ }^{1}$ and László Hornok ${ }^{1,2}$
}

Author for correspondence: László Hornok. Tel: +36 28 330600. Fax: + 3628330482.

\author{
1 Agricultural Biotechnology \\ Center, 2101 Gódölló, PO \\ Box 411, Hungary \\ 2 Department of \\ Microbiology, Agricultural \\ University, Gódolló, \\ Hungary
}

\begin{abstract}
Variations in trichothecene patterns of 26 Fusarium sporotrichioides isolates from different plant and geographic origins showed no correlation with electrophoretic karyotype polymorphisms. When intact chromosomes were examined, interisolate karyotype differences were observed only in the minichromosome range. Further polymorphisms were revealed in Noti-digested samples. By summing the Notl fragments the average genome size of $F$. sporotrichioides was estimated to be $20.4 \mathrm{Mb}$. Mini-chromosomes shared common sequences with the larger ones; however, clones (RMS-1 and RMS-2) specific to these structures have also been found. These clones contained no coding region and no promising similarities were observed when they were compared to sequences held at GenBank. Mini-chromosomes in $\boldsymbol{F}$. sporotrichioides constitute a mosaic composed of dispersed repeats and unique sequences. This mosaic structure was maintained in all noninterbreeding, genetically isolated strains examined.
\end{abstract}

Keywords: Fusarium sporotrichioides, electrophoretic karyotype, mycotoxin, trichothecenes, mini-chromosome

\section{INTRODUCTION}

The filamentous fungus Fusarium sporotrichioides occurs on a wide range of cereal plants as a secondary invader or seriously contaminates foods and fodder as a storage organism. This ubiquitous species produces various types of toxic 12,13-epoxy-trichothecenes (Visconti et al., 1985) that may cause losses in animal husbandry and pose public health hazards. Patterns of trichothecene production vary considerably among strains and during long-term culture maintenance; the decline of toxigenic capability after repeated subculturing is frequently observed.

The importance of F. sporotrichioides has prompted classical and molecular genetic investigations. As this fungus is strictly asexual, other mechanisms of variability were supposed to exist. Heterokaryons were successfully induced between auxotrophs, but they proved to be unstable; parasexuality was not demonstrated because prototrophic recombinants could not be isolated from the heterokaryons (Cullen et al., 1983). A trichodiene synthase gene (tox5) which specifies the key-enzyme of the trichothecene biosynthesis was isolated and sequenced

The GenBank accession numbers for the nucleotide sequence data reported in this paper are U10464 for RMS-1 and U10465 for RMS-2. from this species (Hohn \& Beremand, 1989). In a more recent study we have used electrophoretic karyotyping to characterize eight members of the Fusarium genus (Fekete et al., 1993). The genome size of F. sporotrichioides as represented by one isolate was estimated to be $27.7 \mathrm{Mb}$ and the number of chromosomes appeared to be six; four of them were very similar in size and therefore difficult to separate. One distinct mini-chromosome $(1 \cdot 2 \mathrm{Mb})$ was also identified in this fungus.

The purposes of the present work were to study the extent of infraspecific karyotype variation in F. sporotrichioides, to find correlation, if any, between toxin production patterns and karyotype differences, to provide more exact data on the genome size of this fungus by digesting the chromosomal DNA preparations with octanucleotiderecognizing restriction endonucleases, and to clone DNA fragments specific to mini-chromosomes of this fungus and suitable for tracing the origin of these structures.

\section{METHODS}

Fungal strains. The geographic origin, habitat and strain numbers of the 26 isolates of $F$. sporotrichioides are given in Table 1. Other species of the genus, namely Fusarium avenaceum, Fusarium chlamydosporum, Fusarium pallidoroseum, Fusarium poae and Fusarium tricinctum, were isolated and identified by us; Fusarium camptoceras and Fusarium fusarioides were kindly sup- 
Table 1. Origins, sources and trichothecene production of $F$. sporotrichioides strains

\begin{tabular}{|c|c|c|c|c|c|c|c|c|c|c|c|}
\hline \multirow{2}{*}{$\begin{array}{l}\text { Strain } \\
\text { number }\end{array}$} & \multirow[t]{2}{*}{ Origin } & \multirow[t]{2}{*}{ Source* } & \multicolumn{9}{|c|}{ Trichothecenes $\left(\mu \mathrm{g} \mathrm{g}^{-1}\right) \dagger$} \\
\hline & & & MAS & DAS & T-2te & NEO & T-2tr & $\mathbf{T}-2$ & H'T-2 & acT-2 & iT-2 \\
\hline A-2 & Maize, kernel, Hungary, 1990 & Own collection & - & + & $7 \cdot 0$ & $30 \cdot 0$ & - & $75 \cdot 3$ & $25 \cdot 0$ & + & - \\
\hline$A-5$ & Maize, cob, Hungary, 1990 & Own collection & - & + & $6 \cdot 0$ & $132 \cdot 2$ & + & $311 \cdot 0$ & $27 \cdot 9$ & $6 \cdot 0$ & - \\
\hline A-6 & Wheat, kernel, Hungary, 1990 & Own collection & - & - & + & $2 \cdot 6$ & - & 6.5 & - & - & - \\
\hline A-16 & Wheat, kernel, Hungary, 1990 & Own collection & - & - & - & $8 \cdot 0$ & - & + & - & - & - \\
\hline A-17 & Wheat, kernel, Hungary, 1990 & Own collection & - & + & + & $47 \cdot 0$ & - & $21 \cdot 6$ & - & - & - \\
\hline TA-2 & Wheat, kernel, Hungary, 1991 & Own collection & - & - & - & - & - & $119 \cdot 0$ & - & - & - \\
\hline ТA-6 & Wheat, kernel, Hungary, 1991 & Own collection & - & $10 \cdot 6$ & - & $16 \cdot 2$ & - & $22 \cdot 0$ & - & - & - \\
\hline $22-205$ & Wheat, kernel, Hungary, 1970 & Own collection & - & - & - & $9 \cdot 4$ & - & $9 \cdot 6$ & + & - & - \\
\hline KF-1715 & Wheat, kernel, Poland, 1992 & J. Chelkowski & - & + & $15 \cdot 4$ & $240 \cdot 0$ & $11 \cdot 7$ & $520 \cdot 0$ & $15 \cdot 0$ & + & + \\
\hline M-1-1 & - & Y. Ueno & - & - & $8 \cdot 2$ & $56 \cdot 3$ & - & $32 \cdot 3$ & $10 \cdot 0$ & - & - \\
\hline $\mathrm{I}-391$ & Corn, Italy, 1990 & A. Logrieco & - & - & $10 \cdot 0$ & $533 \cdot 3$ & $10 \cdot 3$ & $1120 \cdot 0$ & $393 \cdot 0$ & $10 \cdot 6$ & - \\
\hline $\mathrm{I}-707$ & - & A. Logrieco & - & $7 \cdot 0$ & + & $3 \cdot 0$ & - & $27 \cdot 6$ & + & - & - \\
\hline $1-710$ & - & A. Logrieco & - & - & - & $33 \cdot 0$ & - & $24 \cdot 8$ & $11 \cdot 7$ & - & - \\
\hline TASP-1 & Wheat, kernel, Hungary, 1991 & Own collection & - & - & - & $25 \cdot 0$ & - & $58 \cdot 4$ & $11 \cdot 8$ & - & - \\
\hline TASP-2 & Wheat, kernel, Hungary, 1991 & Own collection & - & - & $5 \cdot 7$ & $78 \cdot 0$ & $10 \cdot 9$ & $253 \cdot 2$ & $35 \cdot 6$ & $4 \cdot 8$ & - \\
\hline TASP-3 & Wheat, kernel, Hungary, 1991 & Own collection & - & - & - & $496 \cdot 0$ & - & $247 \cdot 8$ & $247 \cdot 5$ & - & - \\
\hline TASP-4 & Wheat, kernel, Hungary, 1991 & Own collection & - & - & - & $58 \cdot 6$ & + & $52 \cdot 5$ & $19 \cdot 1$ & - & - \\
\hline TASP-5 & Wheat, kernel, Hungary, 1991 & Own collection & - & + & - & $4 \cdot 4$ & - & $7 \cdot 7$ & - & - & - \\
\hline TASP-6 & Wheat, kernel, Hungary, 1991 & Own collection & - & - & - & 4.5 & - & $11 \cdot 5$ & + & - & - \\
\hline TASP-7 & Wheat, kernel, Hungary, 1991 & Own collection & + & $8 \cdot 2$ & + & $342 \cdot 3$ & $12 \cdot 5$ & $616 \cdot 8$ & $448 \cdot 0$ & - & - \\
\hline TASP-8 & Wheat, kernel, Hungary, 1991 & Own collection & - & - & - & $25 \cdot 0$ & - & $21 \cdot 0$ & $12 \cdot 0$ & - & - \\
\hline TASP-9 & Wheat, kernel, Hungary, 1991 & Own collection & - & + & $15 \cdot 7$ & $24 \cdot 2$ & $5 \cdot 5$ & $29 \cdot 5$ & $8 \cdot 5$ & - & - \\
\hline TASP-10 & Wheat, kernel, Hungary, 1991 & Own collection & - & - & - & $42 \cdot 2$ & - & $29 \cdot 6$ & $13 \cdot 1$ & - & - \\
\hline TASP-11 & Wheat, kernel, Hungary, 1991 & Own collection & - & $10 \cdot 3$ & $9 \cdot 6$ & $8 \cdot 2$ & $4 \cdot 5$ & $21 \cdot 3$ & $19 \cdot 5$ & - & - \\
\hline TASP-12 & Wheat, kernel, Hungary, 1991 & Own collection & - & - & + & $167 \cdot 6$ & - & $183 \cdot 7$ & $26 \cdot 0$ & - & - \\
\hline TASP-13 & Wheat, kernel, Hungary, 1991 & Own collection & - & $15 \cdot 6$ & + & $178 \cdot 6$ & $20 \cdot 0$ & $162 \cdot 8$ & $34 \cdot 3$ & - & - \\
\hline
\end{tabular}

- , Not detected.

+ , Detected in trace amounts.

* J. Chelkowski, Agricultural University, Warsaw, Poland; Y. Ueno, Science University of Tokyo, Japan; A. Logrieco, Istituto Tossine e Micotossine da parassiti vegetali, Bari, Italy.

† Abbreviations: MAS, 15-monoacetoxyscirpenol; DAS, 4,15-diacetoxyscirpenol; T-2te, T-2 tetraol; NEO, neosolaniol; T-2tr, T-2 triol; T2, T-2 toxin; HT-2, HT-2 toxin; acT-2, acetyl T-2 toxin; iT-2, iso-T-2 toxin.

plied by S. Chambers (Victorian Plant Research Institute, Burnley, Australia) and C. Booth (International Mycological Institute, Kew, England), respectively.

Mycotoxin identification. F. sporotrichioides isolates were grown on rice grains enriched with peptone solution (Lee et al., 1986). Trichothecenes were directly extracted with an acetonitrile/ water mixture (Sugiura et al., 1990); the filtered extract was concentrated by evaporating under vacuum, passed through an LC-18 SPE tube (Supelco), then evaporated again to dryness. The residue was dissolved in dichloromethane, transferred to an LC-CN SPE tube (Supelco) and eluted with acetonitrile. Derivatives were produced by using trimethylsilyl $N, N$ dimethylcarbamate (Fluka) according to the method of Kientz \& Verweij (1986) and analysed by gas chromatography (GCFID, CP 9000, Chrompack) on a CP SIL 5CB capillary column (Chrompack). Mycotoxins were identified and quantified by means of the following standards: 3-acetyldeoxynivalenol, 15acetyldeoxynivalenol, 3-acetyl-diacetoxyscirpenol, acetyl T-2 toxin, deoxynivalenol, 4,15-diacetoxyscirpenol, fusarenon-X, HT-2 toxin, iso-T-2 toxin, 15-monoacetoxyscirpenol, neosolaniol, scirpentriol, T-2 tetraol, T-2 toxin, T-2 triol (Sigma) and nivalenol (Serva). Detection limits of these trichothecenes ranged from 1 to $8 \mu \mathrm{g}$ (g culture dry weight) ${ }^{-1}$. Each extract was analysed in two separate experiments.

Karyotype analysis. Protoplasts were isolated as described previously by Nagy \& Hornok (1994). Chromosomal DNA bands were separated using the contour-clamped homogeneous electric field dynamically regulated II (CHEF-DR II) system (Bio-Rad) at $9{ }^{\circ} \mathrm{C}$ in circulated $0.5 \times \mathrm{TAE}(40 \mathrm{mM}$ Tris-acetate, $1 \mathrm{mM}$ EDTA, $\mathrm{pH} \mathrm{8.3)} \mathrm{buffer.} \mathrm{Concentrations} \mathrm{of} \mathrm{agarose}$ (chromosomal grade, Bio-Rad), voltages, pulse rates and run times were varied to obtain optimal separation; these data are given in Results. Size standards were Schizosaccharomyces pombe and Saccharomyces cerevisiae chromosomal DNA (Bio-Rad), lambda concatemer ladder (Boehringer) and lambda DNA/HindIII fragments (Amersham). Photographic negatives of the ethidium-bromide-stained gels were scanned with a densitometer (Bosch TYK 92D). Chromosome numbers and sizes were estimated after three independent fractionations.

Restriction enzyme digestion of chromosomal DNA. Agarose plugs containing intact chromosomal DNA were washed twice for $10 \mathrm{~min}$ in TE $(10 \mathrm{mM}$ Tris $/ \mathrm{HCl}, 1 \mathrm{mM}$ EDTA, $\mathrm{pH} 8 \cdot 0)$. 
They were then washed twice in $150 \mu$ l restriction enzyme buffers (as recommended by the manufacturers) and incubated for $16 \mathrm{~h}$ at $37^{\circ} \mathrm{C}$ in the same buffers containing $35 \mathrm{U} \mathrm{PmeI}$, SfiI (New England Biolabs) or NotI (Amersham). Chromosomal fragments generated from restriction enzyme digestion were separated by using the CHEF-DR II system. Other restriction endonucleases (BamHI, EcoRI, HindIII, SacI, XboI) were obtained from Amersham and used according to the manufacturer's recommendations.

Blotting and hybridization. Gels were transferred onto Hybond-N nylon membrane (Amersham) according to Southern (1975). Pooled DNA probes as well as a $1 \cdot 1 \mathrm{~kb}$ $X$ boI-SacI fragment of the tox 5 gene (donated by T. M. Hohn, USDA, ARS, Peoria, Illinois, USA) were labelled with $\left[\alpha^{32} \mathrm{P}\right] \mathrm{dCTP}$ by nick-translation (Sambrook et al., 1989) using the Nick Translation System (Gibco-BRL). Random clones from various strains of $F$. sporotrichioides were also labelled with $\left[\alpha^{32} \mathrm{P}\right] \mathrm{dCTP}$ by random priming (Sambrook et al., 1989) using random hexanucleotide primer (New England Biolabs).

Cloning and sequencing of DNA fragments from minichromosomes. After separation of chromosome-sized DNAs by pulsed-field gel electrophoresis, they were cut from the gel and isolated as described by Maniatis et al. (1982). DNA fragments digested with $B a m \mathrm{HI}$, EcoRI and HindIII were cloned in Bluescript pSK (M13-), Amp ${ }^{\mathrm{r}}$ (Short et al., 1988), according to the procedures outlined by Sambrook et al. (1989). Competent cells of Escherichia coli DH $5 \alpha$ were prepared and transformed as described by Maniatis et al. (1982). Clones RMS-1 and RMS-2 were sequenced by the dideoxy chain-termination method of Sanger et al. (1977) using the Sequenase Version 2.0 DNA sequencing kit (USB); $\left[{ }^{35} \mathrm{~S}\right] \mathrm{dATP} \alpha \mathrm{S}$ was obtained from Amersham. Conditions used for sequencing were as described in the Sequenase brochure (USB).

\section{RESULTS}

\section{Mycotoxin production}

The production of trichothecenes by 26 isolates of $F$. sporotrichioides is summarized in Table 1 . All strains were able to produce $\mathrm{T}-2$ toxin and all but one synthesized neosolaniol. On the other hand, two compounds, 15monoacetoxyscirpenol and iso-T-2 toxin, were identified in trace amounts and only in two isolates. Scirpentriol, 3acetyldeoxynivalenol, deoxynivalenol, 3-acetyldeoxynivalenol, 15-acetyldeoxynivalenol, nivalenol and fusarenon-X could not be detected in any sample. There were great qualitative and quantitative differences in toxigenic capabilities among strains. In the case of the major compounds (neosolaniol and T-2 toxin) the quantitative variations predominated: neosolaniol was produced from 2.6 to $533.3 \mu \mathrm{g} \mathrm{g}^{-1}$ while levels of T-2 toxin varied between 6.5 and $1120.0 \mu \mathrm{g} \mathrm{g}^{-1}$. Several strains were unable to synthesize HT-2 toxin, but others accumulated high amounts of this compound. Differences in the trichothecene patterns seem to be independent of the geographic or plant origins of the strains.

\section{Electrophoretic karyotype analysis}

When preparations of chromosomal DNA of F. sporotrichioides isolates were subjected to pulsed-field gel electrophoresis under conditions where $S$. pombe chromosomal DNAs were clearly resolved $(0 \cdot 6 \%$ agarose, voltage
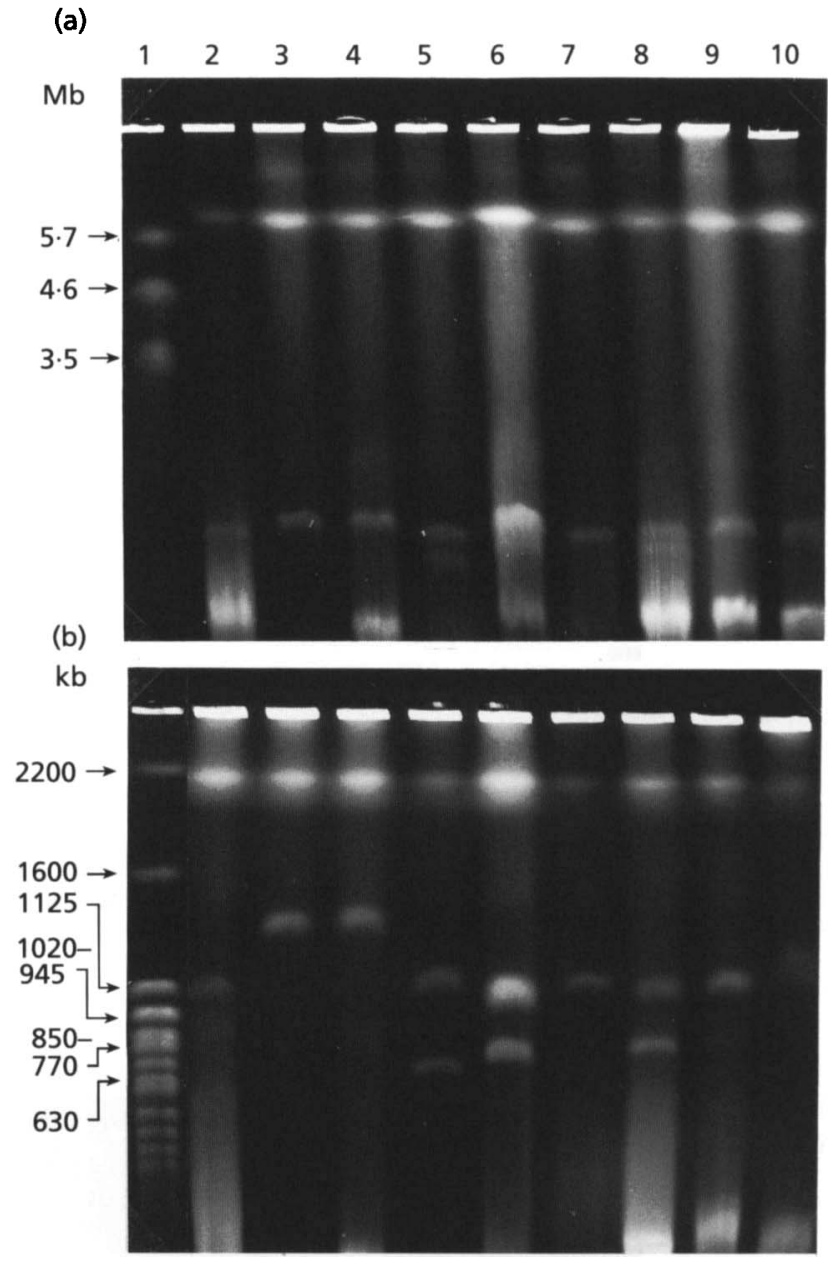

Fig. 1. Separation of chromosome-sized DNAs of selected $F$. sporotrichioides strains. Lanes: $1, S$. pombe (S. cerevisiae) size standards; 2, TA-2; 3, KF-1715; 4, TASP-1; 5, TASP-2; 6, TASP-3; 7, TASP-4; 8, TASP-5; 9, TASP-6; 10, TASP-7. (a) Electrophoretic conditions for separation of the larger chromosomes. (b) Conditions to separate mini-chromosomes.

$45 \mathrm{~V}$, switching time $3 \mathrm{~s}$ for $30 \mathrm{~h}$, then ramped from 1500 to $3600 \mathrm{~s}$ for $162 \mathrm{~h}$ at $40 \mathrm{~V}$ ), each gave a similar overall karyotype (Fig. 1a). One weak and diffuse band appeared at around $7 \mathrm{Mb}$, another strong and thick band was observed at around $6 \mathrm{Mb}$ and one or two bands were detected in the lower region. Recently we compared single isolates of several closely related species of the genus Fusarium (Fekete et al., 1993) and the same karyotype was obtained for F. sporotrichioides; based on these comparisons the largest band was identified as one chromosome and the thick, bright band around $4 \cdot 6-5 \cdot 4 \mathrm{Mb}$ was estimated to be four co-migrating chromosomes of the same or similar sizes. The present investigation showed that this chromosomal pattern is typical of $F$. sporotrichioides as no interstrain variation was detected in the large chromosome range.

Chromosomes smaller than $2.0 \mathrm{Mb}$ were separated in $0.8 \%$ agarose by using switching times of $120 \mathrm{~s}$ for $12 \mathrm{~h}$ then $180 \mathrm{~s}$ for another $12 \mathrm{~h}$ at $160 \mathrm{~V}$ (Fig. 1b). This 


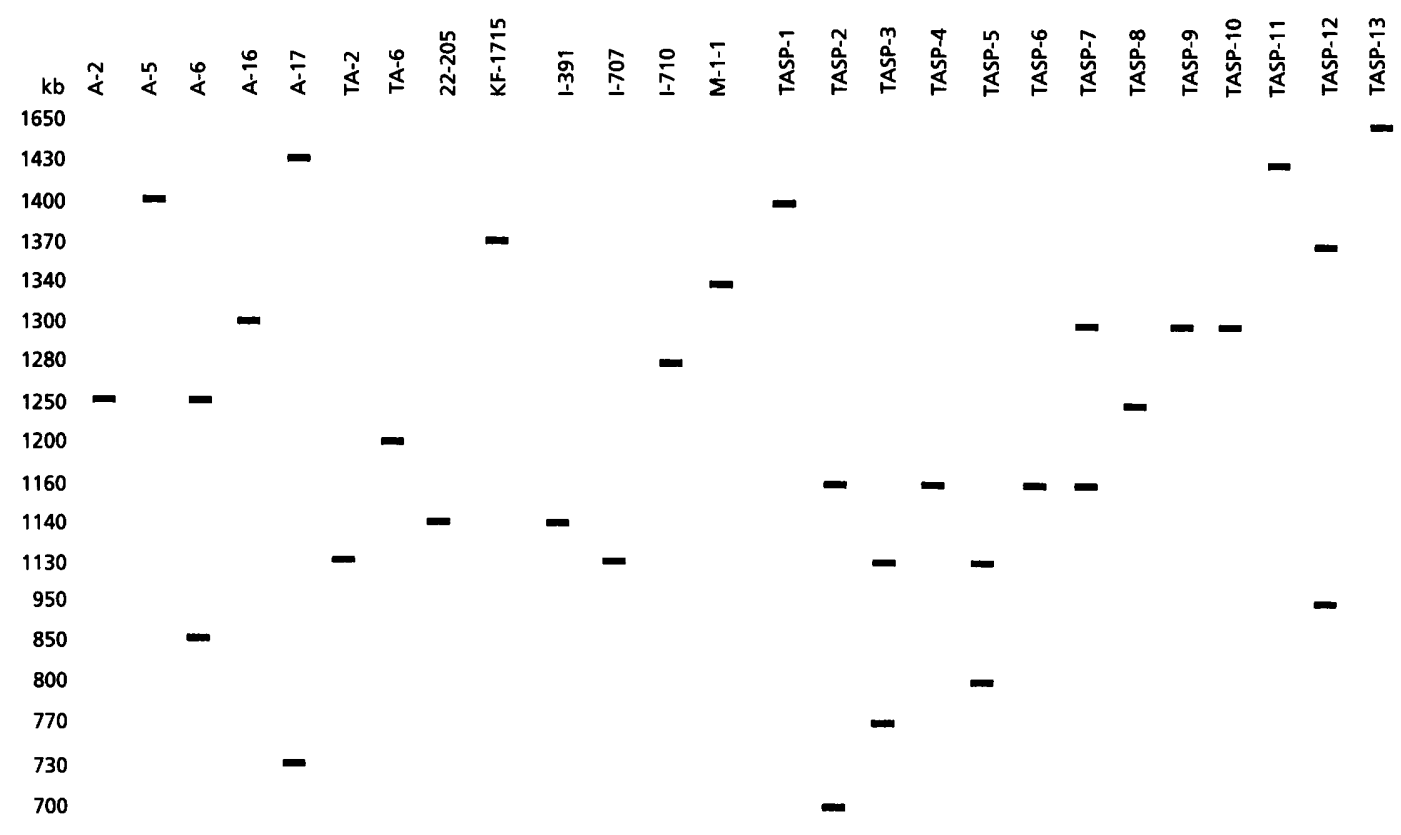

Fig. 2. Scheme of mini-chromosome band profiles of the $F$. sporotrichioides strains. The chromosome bands stained with ethidium bromide are presented as bars positioned according to their molecular size in $\mathrm{kb}$.

(a)

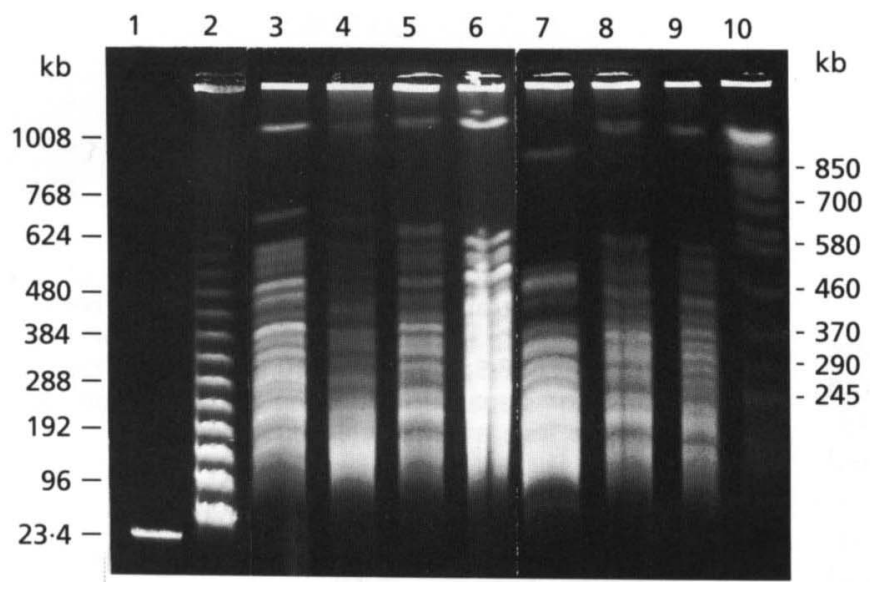

(b)

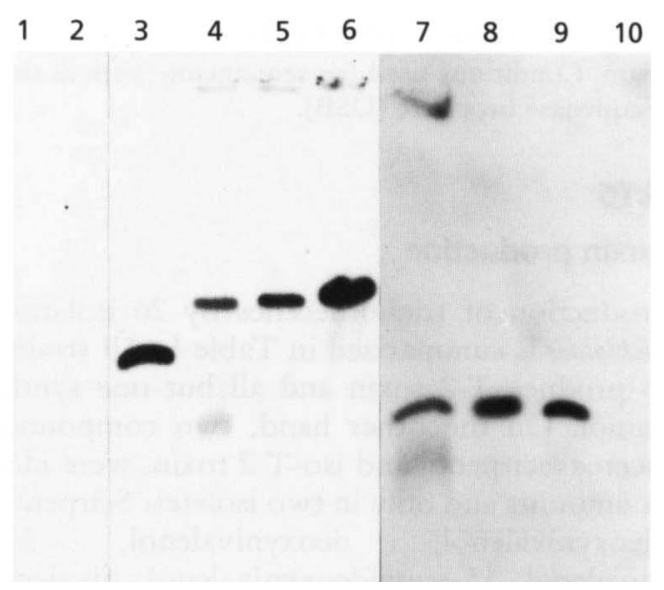

Fig. 3. Notl-digested chromosome-sized DNAs of selected $F$. sporotrichioides strains. Lanes: 1, lambda Hindlll fragments; 2. lambda ladder; 3, M-1-1; 4, KF-1715; 5, I-707; 6, A-2; 7, TASP-2; 8, TASP-3; 9, TASP-10; 10, S. cerevisiae. (a) Ethidiumbromide-stained gel. (b) The same gel probed with tox5. Separation conditions: agarose concentration $1.0 \%$ (w/v); $165 \mathrm{~V}$; ramped switching time from 20 to $90 \mathrm{~s}$ for $23 \mathrm{~h}$.

electrophoresis revealed a dissimilar banding pattern for each strain. The mini-chromosomes resolved by means of these parameters ranged from approximately $700 \mathrm{~kb}$ for the smallest band in strain TASP-2 to a $1650 \mathrm{~kb}$ band in strain TASP-13 (Fig. 2).

Thus, if intact chromosomes of different isolates were compared, infraspecific polymorphisms could be detected only in the mini-chromosome range. Further polymorphisms were expected to be resolved by digesting the agarose-embedded DNA with restriction enzymes that recognize an 8 bp sequence. Digestion with $P m e I$ and $S$ fi resulted in a strong smear, therefore the exact identification of the bands was impossible. However, NotI generated 31-32 fragments ranging from 40 to $2380 \mathrm{~kb}$ in size and revealed detectable polymorphisms among strains (Fig. 3a). Polymorphisms were more evident when gels were hybridized with a probe containing a $1.1 \mathrm{~kb}$ XboI-SacI fragment of the tox 5 gene (Fig. 3b).

A more precise estimation of the genome size of $F$. sporotricbioides was attempted by summing the NotI 
Table 2. Sizes of Notl fragments of the chromosomes of selected $F$. sporotrichioides strains

\begin{tabular}{|c|c|c|c|c|c|}
\hline \multirow{2}{*}{$\begin{array}{c}\text { Fragment } \\
\text { number }\end{array}$} & \multicolumn{5}{|c|}{ Strains } \\
\hline & KF-1715 & I-707 & M-1-1 & TASP-3 & TASP-7 \\
\hline 1 & 2150 & 2380 & 1920 & 2310 & 2110 \\
\hline 2 & 1470 & 730 & 1570 & $580 \dagger$ & 1660 \\
\hline 3 & $650^{*}$ & 650 & 710 & 550 & 600 \\
\hline 4 & 550 & 600 & 610 & 540 & 580 \\
\hline 5 & 530 & $580^{*}$ & 580 & 520 & 570 \\
\hline 6 & 520 & 540 & 540 & $500^{*}$ & 550 \\
\hline 7 & $490^{*}$ & $500 *$ & $510 \dagger$ & $470^{*}$ & $540^{*}$ \\
\hline 8 & $470^{*}$ & $480^{*}$ & 480 & $440 \dagger$ & 520 \\
\hline 9 & 460 & $460^{*}$ & 460 & $420^{\circ}$ & $500^{*}$ \\
\hline 10 & $440^{*}$ & 450 & 440 & $400^{*}$ & 480 \\
\hline 11 & 420 & $440^{*}$ & $410 \dagger$ & $370 \dagger$ & $470^{*}$ \\
\hline 12 & $400 \dagger$ & 430 & $400^{*}$ & $350 \dagger$ & 450 \\
\hline 13 & $390^{*}$ & $400 \dagger$ & $380^{*}$ & 340 & $430 \dagger$ \\
\hline 14 & $370+$ & 390 & $370^{*}$ & $320 \dagger$ & $410^{*}$ \\
\hline 15 & $350 \dagger$ & $370 \dagger$ & $350^{*}$ & 310 & $380 \dagger$ \\
\hline 16 & $330^{*}$ & 360 & 340 & $300 \dagger$ & $350^{*}$ \\
\hline 17 & $300^{*}$ & 350 & 330 & 290 & $330 t$ \\
\hline 18 & $290^{*}$ & 330 & $320 \dagger$ & $280^{*}$ & $310^{*}$ \\
\hline 19 & $270 \dagger$ & $310^{*}$ & 310 & $270 \dagger$ & $290 \dagger$ \\
\hline 20 & 260 & $290^{*}$ & $300^{*}$ & $260^{*}$ & $270 \dagger$ \\
\hline 21 & $250^{*}$ & $270 \dagger$ & 290 & $250 \dagger$ & $250 \dagger$ \\
\hline 22 & $240^{*}$ & 260 & $280 \dagger$ & $240 \dagger$ & $240^{*}$ \\
\hline 23 & $230^{*}$ & $250^{*}$ & $260 *$ & $220^{*}$ & $225^{*}$ \\
\hline 24 & $215^{*}$ & $240^{*}$ & $240 \dagger$ & $200 \dagger$ & $205^{*}$ \\
\hline 25 & $200^{*}$ & $230^{*}$ & $230 \dagger$ & $180^{*}$ & 170 \\
\hline 26 & $175^{*}$ & 210 & 205 & $130^{*}$ & 150 \\
\hline 27 & $140^{*}$ & $195 *$ & $190^{*}$ & $120^{*}$ & 140 \\
\hline 28 & 100 & $170^{*}$ & $160^{*}$ & 100 & $125^{*}$ \\
\hline 29 & 80 & $140^{*}$ & $125^{*}$ & $85^{*}$ & 110 \\
\hline 30 & 70 & $110^{*}$ & $90 *$ & $70 *$ & 90 \\
\hline 31 & 60 & 90 & 75 & $50^{*}$ & 80 \\
\hline 32 & & 80 & 50 & 40 & \\
\hline $\begin{array}{l}\text { Genome } \\
\text { size }(k b)\end{array}$ & 20460 & 19760 & 20130 & 20640 & 20860 \\
\hline
\end{tabular}

* Two co-migrating fragments present.

† Three co-migrating fragments present.

fragments of selected strains (Table 2). Several bands were identified as doublets or triplets on the basis of ethidium bromide staining intensity as measured by video scanning densitometry. Estimates of total nuclear genome size ranged from 19.76 to $20.86 \mathrm{Mb}$ with an average of $20.37 \mathrm{Mb}$. These values were somewhat smaller than that $(27.7 \mathrm{Mb}$ ) determined earlier for this species (Fekete et al., 1993) and remained under the various values $(22.5-44 \cdot 0 \mathrm{Mb})$ published so far for other filamentous fungi (Skatrud \& Queener, 1989; Debets et al., 1990; Cooley \& Caten, 1991; Talbot et al., 1991; Carter et al., 1992). However, Kim et al. (1993) recently reported a genome size of Fusarium oxysporum f.sp. niveum ranging between 15.9 and $26.0 \mathrm{Mb}$; these values seem to support our estimation.

\section{Cloning and sequencing DNA fragments specific to mini-chromosomes}

Interisolate karyotype differences were observed only in the mini-chromosome range. In order to obtain further information on these structures a $1.43 \mathrm{Mb}$ minichromosome of strain A-17 was isolated from the gel and its 3-20 kb Bam HI fragments were nick-translated and hybridized as a pooled DNA probe to Southern blots of the pulsed-field gels. The same experiment was performed using HindIII fragments of the $1.13 \mathrm{Mb}$ minichromosome of strain TASP-3. These probes hybridized strongly both to the large chromosomes and to the small ones of the $26 F$. sporotrichioides strains. Several fragments were cloned and used as probes and the majority of them gave the same results obtained with the pooled DNA probes. However, two clones, a $0.16 \mathrm{~kb} \mathrm{BamHI}$ fragment of the $1.43 \mathrm{Mb}$ mini-chromosome of A-17, and a $0.56 \mathrm{~kb}$ EcoRI fragment of the $1.25 \mathrm{Mb}$ mini-chromosome of strain A-2, named as RMS-1 and RMS-2, respectively, hybridized exclusively to mini-chromosomes (Fig. 4). In those strains that harboured two small chromosomes the probes always hybridized to the larger ones. Several other Fusarium species $(F$. avenaceum, $F$. camptoceras, $F$. chlamydosporum, $F$. fusarioides, $F$. pallidoroseum, $F$. poae, and $F$. tricinctum) closely related to $F$. sporotrichioides were also probed with the pooled DNA probe, as well as with RMS1 and RMS-2, but no signal was observed.

Consequently, RMS- 1 and RMS- 2 are mini-chromosomespecific clones. When their sequences were analysed no coding region was revealed and no promising similarity was observed when they were compared to sequences held at GenBank.

\section{DISCUSSION}

All geographically different $F$. sporotrichioides isolates were able to synthesize several A type trichothecenes in various patterns and amounts. As this species is a well documented trichothecene producer (Thrane, 1989), our results were not unexpected. In a similar survey 11 strains of this fungus were all found to synthesize T-2 toxin (Thrane, 1986) and all 17 isolates were identified as producers of $T$ 2 toxin, HT-2 toxin, and neosolaniol by other workers (Logrieco et al., 1990). On the other hand, Chelkowski et al. (1984) stated that only $40 \%$ of the F. sporotrichioides isolates from Poland were able to produce the major trichothecene mycotoxins.

Extensive karyotype variability within fungal species has frequently been reported. According to a recent hypothesis (Kistler \& Miao, 1992) asexual fungi are more likely to show great chromosomal polymorphisms due to the absence of meiosis, which allows the maintenance of these aberrations. In our experiments electrophoretic karyotypes of the different $F$. sporotrichioides isolates proved to be rather uniform as far as the large chromosomes are concerned. In no way would we explain this finding by the genetic uniformity of the species. The lack of major infraspecific chromosome polymorphisms is more probably due to the unusual karyotype of $F$. sporotrichioides, i.e. the large chromosomes constituting 
(a)

(b)
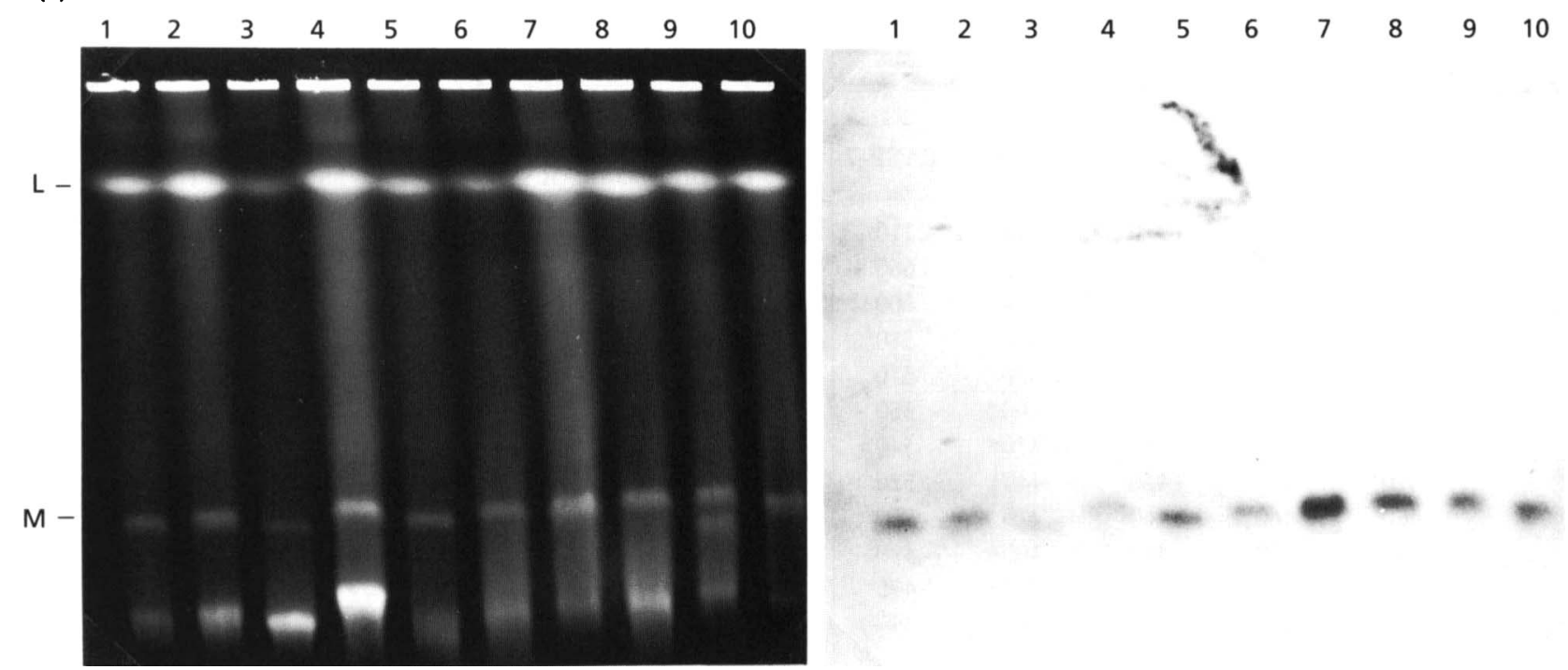

Fig. 4. Electrophoretic karyotypes of selected $F$. sporotrichioides strains probed with the mini-chromosome-specific clone, RMS-1. (a) Ethidium-bromide-stained gel. (b) Southern blot of the same gel. Lanes 1-10: 22-205, I-391, I-707, I-710, TASP8, TASP-9, TASP-10, TASP-11, TASP-12 and TASP-13, respectively. Separation conditions are as given in Fig. 1(a). L, large chromosomes; $\mathrm{M}$, mini-chromosomes.

more than $90 \%$ of the genome are all above $4.5 \mathrm{Mb}$ and fall into the least resolvable region. At the same time, mini-chromosomes greatly varied both in numbers and sizes presenting thus strain-specific patterns. Interisolate karyotype differences restricted to mini-chromosomes have also been identified in the type B isolates of the plant pathogen Colletotrichum gloeosporioides (Masel et al., 1990).

Changes in chromosome structures may result in phenotype modifications. Chromosomal rearrangements were found to be associated with morphological mutations in Candida tropicalis (Suzuki et al., 1991), polymorphic karyotypes were observed in Acremonium cbrysogenum strains differing in $\beta$-lactam antibiotic production (Smith et al., 1991; Walz \& Kück, 1991) and considerable karyotype variation was apparent between and within wheat- and barley-adapted isolates of Septoria nodorum (Cooley \& Caten, 1991). In the present study, however, no correlation was found between toxigenic variability and chromosome polymorphisms.

Many fungi harbour mini-chromosomes. Because of their minuteness and variability they were formerly regarded as the equivalent of the B-chromosomes present in animals or higher plants. Although no essential genes have been detected on these structures, functional genes involved in phytoalexin detoxification were mapped on such a chromosome of Nectria baematococca (Miao et al., 1991). Several mechanisms are hypothesized to explain the origin of mini-chromosomes. They could have arisen by genome rearrangements or through horizontal transfers among different strains of the species. The chromosomal rearrangement theory is supported by homologies found between mini-chromosomes and large chromosomes in Ustilago maydis (Kinscherf \& Leong, 1988), C. gloeosporioides (Masel et al., 1990), and Aspergillus flavus (Keller et al., 1992). The contribution of horizontal transfer is indicated by a recent finding of Masel et al. (1993), who identified a unique mini-chromosome in race 3 isolates of C. gloeosporioides; this chromosome was most probably derived through addition from a genetically distinct strain of this fungus.

In order to investigate the origin of the minichromosomes in F. sporotrichioides, pooled DNA fragments of the 1.43 and $1.13 \mathrm{Mb}$ mini-chromosomes of strains A-17 and TASP-3, respectively, were hybridized to karyotypes of the 26 strains. The strong hybridization between these DNA probes and the large chromosomes of each isolate indicates that mini-chromosomes share common sequences with the large ones in this species. However, sequences specific to mini-chromosomes also exist. Since neither sexual nor parasexual recombination has until now been proven in F. sporotrichioides, the reality of chromosome transfers between different isolates of this fungus is very small. The probability of an interspecific transfer is even more unlikely if we consider the complete nonhomology that we found when related species of the genus Fusarium were probed with pooled minichromosome DNAs, as well as with RMS-1 and RMS-2. The most possible explanation of the origin of the minichromosomes is that they are results of major genome rearrangements. During these processes minichromosomes were formed as mosaics of dispersed repeats and unique sequences. These rearrangements probably occurred earlier in the evolution of this species as their results were detected in all strains. The universal occurrence of mini-chromosomes in F. sporotrichioides, as well as the finding that the mosaic structure composed of dispersed repeats and unique sequences was maintained in many non-interbreeding, genetically isolated strains, 
strongly suggests that these structures are useful components of the genome.

\section{ACKNOWLEDGEMENTS}

This work was supported by a grant from the OTKA (1913/81). T. Bagdány and G. Takács are thanked for skilful technical assistance. The authors are grateful to Drs J. Chelkowski, A. Logrieco and Y. Ueno for supplying Fusarium isolates and to Dr T. M. Hohn for the tox 5 gene.

\section{REFERENCES}

Carter, G. L., Allison, D., Rey, M. W. \& Dunn-Coleman, N. S. (1992). Chromosomal and genetic analysis of the electrophoretic karyotype of Trichoderma reesei: mapping of the cellulase and xylanase genes. Mol Microbiol 6, 2167-2174.

Chelkowski, J., Visconti, A., Solfrizzo, M. \& Bottalico, A. (1984). Formation of mycotoxins by Fusarium species from cereals in Poland. Phytopath Mediterr 23, 43-46.

Cooley, R. N. \& Caten, C. E. (1991). Variation in electrophoretic karyotype between strains of Septoria nodorum. Mol \& Gen Genet 228, 17-23.

Cullen, D., Smalley, E. B. \& Dimond, R. L. (1983). Heterokaryosis in Fusarium tricinctum and F. sporotrichioides. J Gen Microbiol 129, 3035-3041.

Debets, A. J. M., Holub, E. F., Swart, K., van den Broek, H. W. J. \& Bos, C. J. (1990). An electrophoretic karyotype of Aspergillus niger. Mol \& Gen Genet 224, 264-268.

Fekete, C., Nagy, R., Debets, A. J. M. \& Hornok, L. (1993). Electrophoretic karyotypes and gene mapping in eight species of the Fusarium sections Arthrosporiella and Sporotrichiella. Curr Genet 24, 500-504.

Hohn, T. M. \& Beremand, P. D. (1989). Isolation and nucleotide sequence of a sesquiterpene cyclase gene from the trichotheceneproducing fungus Fusarium sporotrichioides. Gene 79, 131-138.

Keller, N. P., Cleveland, T. E. \& Bhatnagar, D. (1992). Variable electrophoretic karyotypes of members of Aspergillus section Flavi. Curr Genet 21, 371-375.

Kientz, C. E. \& Verweij, A. (1986). Trimethylsilylation and trifluoroacetylation of a number of trichothecenes followed by gas chromatographic analysis on fused-silica capillary columns. $J$ Cbromatogr 355, 229-240.

Kim, D. G., Martyn, R. D. \& Magill, C. W. (1993). Chromosomal polymorphism in Fusarium oxysporum f.sp. niveum. Phytopathology 83, 1209-1216.

Kinscherf, T. G. \& Leong, S. A. (1988). Molecular analysis of the karyotype of Ustilago maydis. Chromosoma 96, 427-433.

Kistler, H. C. \& Miao, V. P. W. (1992). New modes of genetic change in filamentous fungi. Annu Rev Phytopatbol 30, 131-152.

Lee, U.-S., Jang, H.-S., Tanaka, T., Toyasaki, N., Sugiura, Y., Oh, Y.J., Cho, C.-M. \& Ueno, Y. (1986). Mycological survey of Korean cereals and production of mycotoxins by Fusarium isolates. Appl Environ Microbiol 52, 1258-1260.

Logrieco, A., Chelkowski, J., Bottalico, A. \& Visconti, A. (1990). Further data on specific trichothecene production by Fusarium sect. Sporotrichiella strains. Mycol Res 94, 587-589.

Maniatis, T., Fritsch, E. F. \& Sambrook, J. (1982). Molecular Cloning: a Laboratory Manual. Cold Spring Harbor, NY: Cold Spring Harbor Laboratory.
Masel, A., Braithwaite, K., Irwin, J. \& Manners, J. (1990). Highly variable molecular karyotypes in the plant pathogen Colletotrichum gloeosporioides. Curr Genet 18, 81-86.

Masel, A. M., Irwin, J. A. G. \& Manners, J. M. (1993). DNA addition or deletion is associated with a major karyotype polymorphism in the fungal phytopathogen Colletotrichum gloeosporioides. Mol \& Gen Genet 237, 73-80.

Miao, V.P.W., Matthews, D. E. \& VanEtten, H. D. (1991). Identification and chromosomal locations of a family of cytochrome P-450 genes for pisatin detoxification in the fungus Nectria baematococca. Mol \& Gen Genet 226, 214-223.

Nagy, R. \& Hornok, L. (1994). Electrophoretic karyotype differences between two subspecies of Fusarium acuminatum. Mycologia 86, 203-208.

Sambrook, J., Fritsch, E. F. \& Maniatis, T. (1989). Molecular Cloning: a Laboratory Manual. Cold Spring Harbor, NY: Cold Spring Harbor Laboratory.

Sanger, F., Nicklen, S. \& Coulson, A. R. (1977). DNA sequencing with chain terminating inhibitors. Proc Natl Acad Sci USA 74, 5463-5467.

Short, J. M., Fernandez, J. M., Sorge, J. A. \& Huse, W. D. (1988). $\lambda$ ZAP: a bacteriophage $\lambda$ expression vector with in vivo excision properties. Nucleic Acids Res 16, 7583-7600.

Skatrud, P. L. \& Queener, S.W. (1989). An electrophoretic molecular karyotype for an industrial strain of Cephalosporium acremonium. Gene 78, 331-338.

Smith, A. W., Collis, K., Ramsden, M., Fox, H. M. \& Peberdy, J. F. (1991). Chromosome rearrangements in improved cephalosporin C-producing strains of Acremonium cbrysogenum. Curr Genet 19, 235-237.

Southern, E. M. (1975). Detection of specific sequences among DNA fragments separated by gel electrophoresis. J Mol Biol $\mathbf{9 8}$, 503-517.

Sugiura, Y., Watanabe, Y., Tanaka, T., Yamamoto, S. \& Ueno, Y. (1990). Occurrence of Gibberella zeae strains that produce both nivalenol and deoxynivalenol. Appl Environ Microbiol 56, $3047-$ 3051.

Suzuki, T., Miyamae, Y. \& Ishida, I. (1991). Variation of colony morphology and chromosomal rearrangement in Candida tropicalis pK233. J Gen Microbiol 137, 161-167.

Talbot, N. J., Oliver, R. P. \& Coddington, A. (1991). Pulsed field gel electrophoresis reveals chromosome length differences between strains of Cladosporium fulvum (syn. Fulvia fulva). Mol \& Gen Genet 229, 267-272.

Thrane, U. (1986). Detection of toxigenic Fusarium isolates by thin layer chromatography. Lett Appl Microbiol 3, 93-96.

Thrane, U. (1989). Fusarium species and their specific profiles of secondary metabolites. In Fusarium Mycotoxins, Taxonomy and Pathogenicity. Topics in Secondary Metabolism, pp. 199-225. Edited by J. Chelkowski. Amsterdam: Elsevier.

Visconti, A., Mirocha, C. J., Bottalico, A. \& Chelkowski, J. (1985). Trichothecene mycotoxins produced by Fusarium sporotrichioides strain P-11. Mycotoxin Res 1, 3-10.

Walz, M. \& Kuck, U. (1991). Polymorphic karyotypes in related Acremonium strains. Curr Genet 19, 73-76.

Received 13 April 1994; revised 11 October 1994; accepted 14 November 1994. 